\title{
Effect of stiffener characteristics on the seismic behavior and fracture tendency of steel shear walls
}

\author{
Osman Shallan, Hassan M. Maaly, Mohammed M. Elgiar \\ Zagarig University, Egypt \\ osmanshalan@yahoo.com, bttps://orcid.org/0000-0002-6471-5561 \\ dr_b_maaly@yahoo.com,bttps://orcid.org/0000-0002-2000-8136 \\ mohamedElgyar07@gmail.com, bttps://orcid.org/0000-0001-8463-7276
}

\author{
Alaa A. El-Sisi \\ University of Missouri, USA; on research leave of Zagarig University, Egypt \\ aep64@mail.missouri.edu, bttps://orcid.org/0000-0001-8190-6100
}

\begin{abstract}
The steel plate shear walls (SPSW) are currently being considered as a lateral load resisting system. A numerical method was proposed to have a comprehensive comparison of seismic behaviors of the plane wall (PW) and stiffened plane wall (SPW) with different stiffener characteristics, having the same weight, by using finite element modeling (FEM). The model was validated by using previously published experimental works. The material and geometric nonlinearity were taken into consideration. In this paper, the effect of using stiffeners with different cross-section shapes and directions will be studied, and key issues, such as load-carrying capacity, stiffness, and energydissipation capacity were discussed in depth. It was found that the proposed SPW with horizontal $\mathrm{L}, \mathrm{T}$, and $\mathrm{U}$ stiffeners could effectively improve loadcarrying capacity by about 4,20 , and $23 \%$, respectively. Diagonally and horizontally SPW with U stiffeners have higher energy-dissipation capacity than PW by about $57,50 \%$, respectively. This method provides a combination of high-performance stiffeners form and material use for improving the seismic behavior of SPW.
\end{abstract}

KEYWORDS. Backbone curve; Energy-dissipation capacity; Hysteretic behavior; Steel plate shear wall; Seismic behavior.

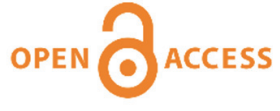

Citation: Shallan, O., Maaly, H. M., Elgiar, M. M., El-Sisi, A. A., Effect of stiffener characteristics on the seismic behavior and fracture tendency of steel shear walls, Frattura ed Integrità Strutturale, 54 (2020) 104-115.

Received: 01.07 .2020

Accepted: 27.07 .2020 Published: 01.10 .2020

Copyright: (C) 2020 This is an open access article under the terms of the CC-BY 4.0, which permits unrestricted use, distribution, and reproduction in any medium, provided the original author and source are credited. 


\section{INTRODUCTION}

7 he SPSW is used in many countries as a lateral load resisting system, due to its advantages over the concrete walls such as high ductility, good seismic behavior, easy retrofit, lightweights, and less footing depth. SPSW consists of the boundary frame and infill plate, as shown in Fig.1.a. Using SPSWs in high rise buildings was studied [1]. To improve the seismic behavior of SPSWs, previous research works were focused on two aspects. Firstly, the design principle of "strong frame, weak wall", in which thin plane wall (PW) had used. Secondly, the stiffened plane wall (SPW), which can be used to avoid large out-of-plane deformations [4, 8, 10, 11]. In this field of researches, all the previous studies focused on a few stiffener details. No comprehensive comparison of seismic performance of SPWs with different stiffener characteristics, having the same weight, had been implemented. Several works were conducted on the PW system to evaluate its seismic performance, load-carrying capacity, stiffness, ductility, and energy dissipation capacity [2,3, 6-18,]. The general results show that Thin PW has early elastic buckling of the infill steel plate. However, PW still has high post-buckling lateral strength. This might be attributed to tension fields, which act like plastic hinges and dissipate more energy [7]. SPSW with a single span and three-stories was experimentally studied [12]. The parametric study included the effect of infill panel, thickness of infill, and span-to-height ratio under cyclic load was investigated. It was found that the thickness of the infill panel has a great influence on seismic behavior. The cyclic test was conducted on thin unstiffened SPSW with four-stories [8]. The results showed good seismic performance, as story drift reached 4\% before reached to failure and high energydissipation capacity. A lot of studies had worked to delay the buckling behavior of PWs using SPWs, which can be stiffened by vertical slits $[8,15,16]$, cross, or diagonal stiffeners $[4,11,13,14]$. It was found that the ductility ratio and energydissipation capacity can be improved by preventing the failure, which can be attributed to the out-of-plane large deformation. An experimental study on the seismic behavior of SPSW with slits was conducted [10]. The test was conducted on 42 walls where the walls were subjected to cyclic and monotonic loads. It was found that using vertical slits improves the seismic behavior of walls. It was also found that walls can reach 3\% drift without failure in cases of width to thickness ratio less than 20. An experimental study was conducted on diagonally stiffened SPSW [2]. It was found that using diagonally SPWs improves seismic behavior and improves the ductility ratio of about $14 \%$ greater than PW. Although a lot of research works focused on the seismic behavior of SPWs there is a need to perform a comparative study to investigate the different behavior of SPWs with different stiffener characteristics, which have the same weight. This paper studied the effect of stiffener cross-section shape L, T, or U and stiffener direction under cyclic loading test Fig. 1.c. This paper studied the cyclic nonlinear behavior of PW and SPWs. Finite element models were developed by using ABAQUS software [19]. Previous experimental work was used to validate the finite element model [20]. Different seismic behavior, load-carrying capacity, stiffness, degradation characteristics, energy dissipation- capacity, fracture tendency and out-of-plane deformations were analyzed and compared for different models. The study aimed to achieve the combination of high-performance stiffeners form and high-performance material.

\section{Problem DesCRiption}

S even models of thin PW and SPW were modeled using ABAQUS software. The parametric study includes the effect of panel type, stiffeners cross-section shape, and direction. Panel type can be plane (PW), or stiffened plane wall (SPW). The SPW can be stiffened by L (SPW-HL), T (SPW-HT), or U shape stiffeners (SPW-HU). The stiffener's direction can be horizontal (SPW-HU), vertical (SPW-VU), cross (SPW-CU), or diagonal stiffeners (SPW-DU). Fig.1.c shows the sections of $\mathrm{L}, \mathrm{T}$, and $\mathrm{U}$ stiffeners. The two legs of $\mathrm{L}$ stiffeners had a height of $120 \mathrm{~mm}$. The flange and height of $T$ stiffeners were $120 \mathrm{~mm}$. The height of $\mathrm{U}$ stiffeners was $120 \mathrm{~mm}$, while the flanges were $60 \mathrm{~mm}$. The thickness of $\mathrm{L}$, $\mathrm{T}$, and U stiffeners was $5 \mathrm{~mm}$. The boundary elements were designed according to AISC Design Guide [21,22]. The beam section was HM $500 \times 300 \times 11 \times 15$ similar to W21 $\times 68$ and the column section was $H W 400 \times 400 \times 13 \times 21$ similar to W14 $\times 132$. Wall panels had a height of $3000 \mathrm{~mm}$, a span of $3000 \mathrm{~mm}$, and a thickness of $5 \mathrm{~mm}$. The models of SPW-HL, SPW-HT, SPW-HU, SPW-VU, and SPW-CU have the same weight. The parametric case study is shown in Tab. 1. Fig. 2 shows the details for different models. 


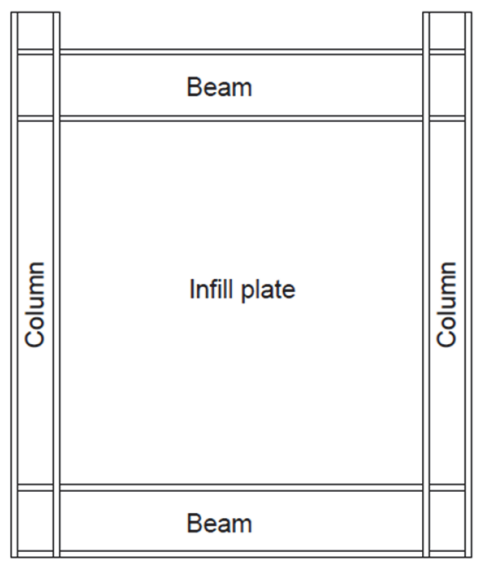

a) PW

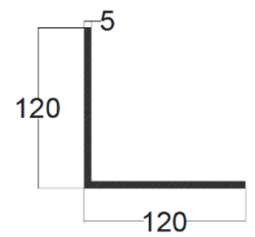

L section

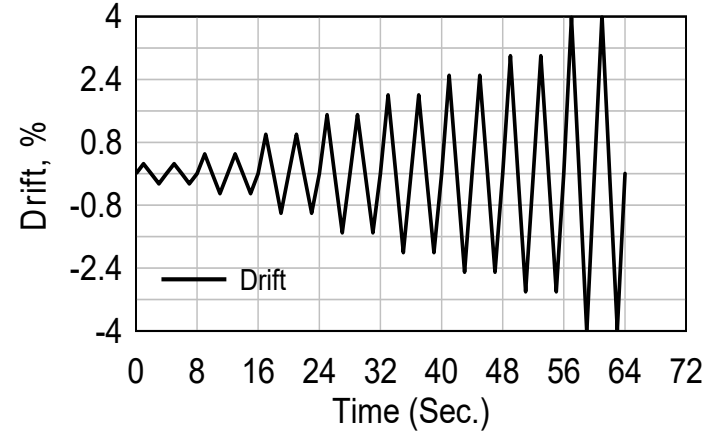

b) Cyclic drifts

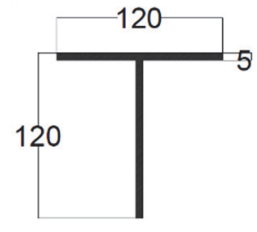

T section

c) Stiffener cross-section shape.

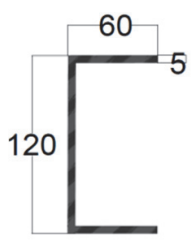

U section

Figure 1: Geometric properties of SPSW.

\begin{tabular}{ccc}
\hline Model ID & Stiffener Direction & Stiffener Cross-section \\
& & None \\
\hline PW & None & $\mathrm{L}$ \\
SPW-HL & Horizontal & $\mathrm{T}$ \\
SPW-HT & Horizontal & $\mathrm{U}$ \\
SPW-HU & Horizontal & $\mathrm{U}$ \\
SPW-DU & Diagonal & $\mathrm{U}$ \\
SPW-VU & Vertical & $\mathrm{U}$ \\
\hline SPW-CU & Cross & \\
\hline
\end{tabular}

Table 1: Parametric Case Study.

\section{FINITE ELEMENT MODELING}

o study the nonlinear behavior of PW, and SPWs, accurate finite element analysis (FEA) should be conducted. The boundary frame, stiffeners, and infill panel were modeled using the 4(four)-node shell element (S4R) with reduced integration [19], to avoid shear locking phenomena. Mechanical properties of materials, the boundary condition of models, and the time history of loading and initial defect are presented in detail as follows.

\section{Mechanical Properties of Steel Materials}

The boundary frame steel, steel plate, and the stiffeners materials have a yielding strength of $345 \mathrm{MPa}$, and $235 \mathrm{MPa}$, respectively. The materials elastic modulus $\mathrm{E}=206 \mathrm{GPa}$, Poisson's ratio $\nu=0.3$ and hardening modulus Eh $=1 / 100 \mathrm{E}$. The behavior of the materials becomes nonlinear, after reaches to maximum yield stress [23-25]. Moreover, due to changes in the deformed shape during the loading process, the geometric nonlinearity should be taken into consideration. The isotropic hardening behavior was considered [19]. 


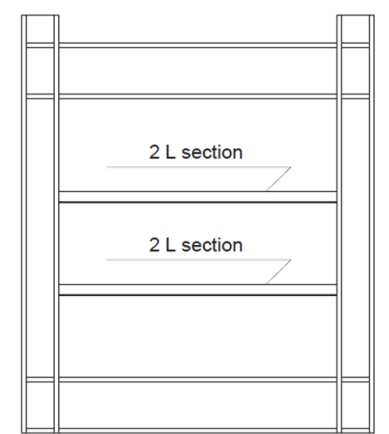

a) SPW-HL

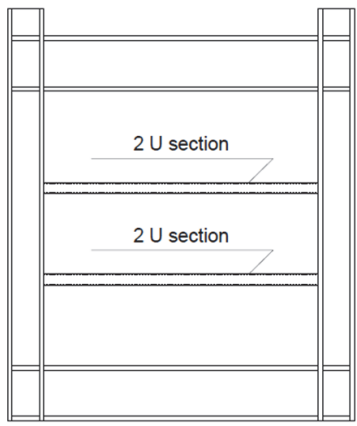

c) SPW-HU

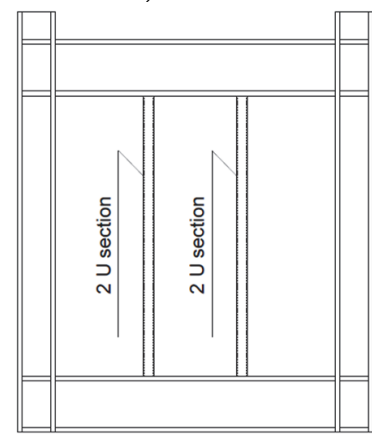

e) SPW-VU

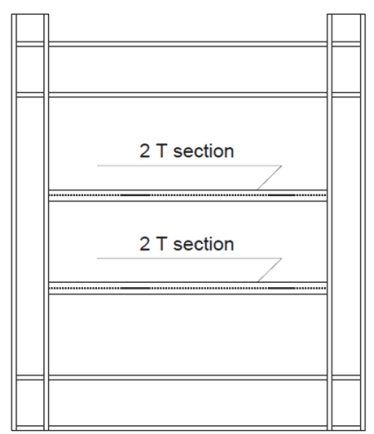

b) SPW-HT

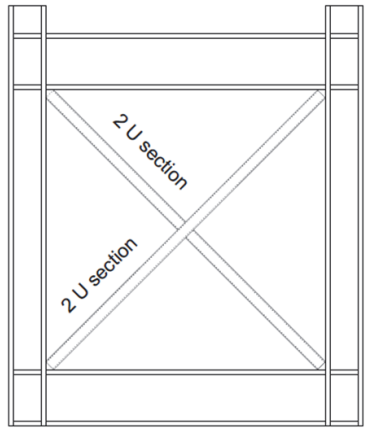

d) SPW-DU

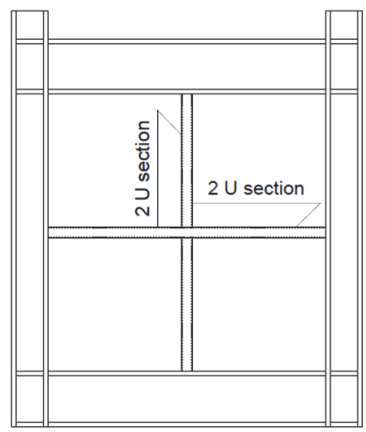

f) SPW-CU

Figure 2: Geometric properties of SPSW

\section{Modal Analysis and Initial Defect}

The out-of-plane initial imperfection, which may occur due to the manufacturing process, storage, and installation process should be taken into consideration in cyclic analysis, thus it might affect the plate strength. Initial imperfection was set as $1 / 1000$ of the plate height. The eigenvalue buckling analysis was used to evaluate the imperfection distribution over the panel by multiplying the major buckling modes by the scale factor.

\section{Boundary Conditions and History Loading}

The nonlinear cyclic analysis was conducted on groups of thin PW and SPWs. The lateral displacement was applied to the exterior column flange. The lateral displacement increased gradually to produce drift ratios of $0.25 \%, 0.5 \%, 1 \%, 1.5 \%, 2 \%$, $2.5 \%, 3 \%$ and $4 \%$. The amplitudes were repeated twice, as shown in Fig. 1.b. The column base regions had a fixed boundary condition, in which all these nodes restrained in all the six degrees of freedom. The out-of-plane displacement for the nodes of the beam centerline and all nodes of the column-beam connections were constrained, to prevent the out-of-plane buckling of the whole system. 


\section{EXPERIMENTAL WORK DETAILS AND NUMERICAL MODEL VALIDATION}

o verify the accuracy of numerical simulation, quasi-static tests were conducted on Park's experiment test [20]. Five unstiffened steel plate shear wall specimens with a single bay and three stories were tested in reference [20]. The experimental test of WC4T was selected for validation in this paper. The span, height, and thickness of the plates were $1500,1000 \mathrm{~mm}$, and $5 \mathrm{~mm}$, respectively. The internal beams section was $H 200 \times 200 \times 16 \times 16 \mathrm{~mm}$, the top beam was $\mathrm{H} 400 \times 200 \times 16 \times 16$ and columns were $\mathrm{H} 250 \times 250 \times 9 \times 12$. The material of infill panels and boundary elements was SM490 with yield stress fy $=330 \mathrm{MPa}$. The cyclic constitutive model was used to simulate the cyclic hardening, local buckling, and degradation characteristics due to cyclic loading. The Chaboche constitutive model [26,27] is adopted therefore, the combined hardening behavior was considered [19]. The cyclic hardening parameters of the material are shown in Tab. 2; where $C_{1}, C_{2}, C_{3}$, and $C_{4}$ are the kinematic hardening modulus, $\gamma_{1}, \gamma_{2}, \gamma_{3}$, and $\gamma_{4}$ are the rates at which hardening modulus decreases with the plastic strain, $\mathrm{Q}_{\infty}$ is the maximum change in the size of the yield surface and $\mathrm{b}$ is the rate at which initial yield stress change with the plastic strain. The initial out of plane defect was selected 1/1000 height of steel plate. "Imperfection" command was used to modify the coordinates of plat's nodes by multiply the major buckling modes by a scale factor. The bottom of the model had a fixed boundary condition. The cyclic horizontal displacements were applied in the middle of the upper beam using a reference point.

\begin{tabular}{cccccccccc}
\hline $\mathrm{Q}_{\infty}, \mathrm{N} / \mathrm{mm}^{2}$ & $\mathrm{~b}$ & $\mathrm{C}_{1}, \mathrm{~N} / \mathrm{mm}^{2}$ & $\gamma_{1}$ & $\mathrm{C}_{2}, \mathrm{~N} / \mathrm{mm}^{2}$ & $\gamma_{2}$ & $\mathrm{C}_{3}, \mathrm{~N} / \mathrm{mm}^{2}$ & $\gamma_{3}$ & $\mathrm{C}_{4}, \mathrm{~N} / \mathrm{mm}^{2}$ & $\gamma_{4}$ \\
21 & 1.2 & 7993 & 175 & 6773 & 116 & 2854 & 34 & 1450 & 29 \\
\hline
\end{tabular}

Table 2: Material hardening parameters.

The load-Horizontal displacement curve for the experimental test and present finite element modeling was compared in Fig. 3, which shows a good agreement with the experimental results. Tab. 3 shows the cyclic results of the experimental test and present FEA for the WC4T specimen. Where $\mathrm{V}_{\max }$ is the load-carrying capacity and $\mathrm{K}_{\mathrm{i}}$ is the initial stiffness of the specimen. From Fig. 3 and Tab. 3, it can be concluded that the present FEA shows a difference in the initial stiffness by about $1.4 \%$ and a difference in load-carrying capacity by about $2.8 \%$ in the positive direction. It can be seen that the current numerical simulation can be used to predict the nonlinear behavior of SPSWs with acceptable accuracy.

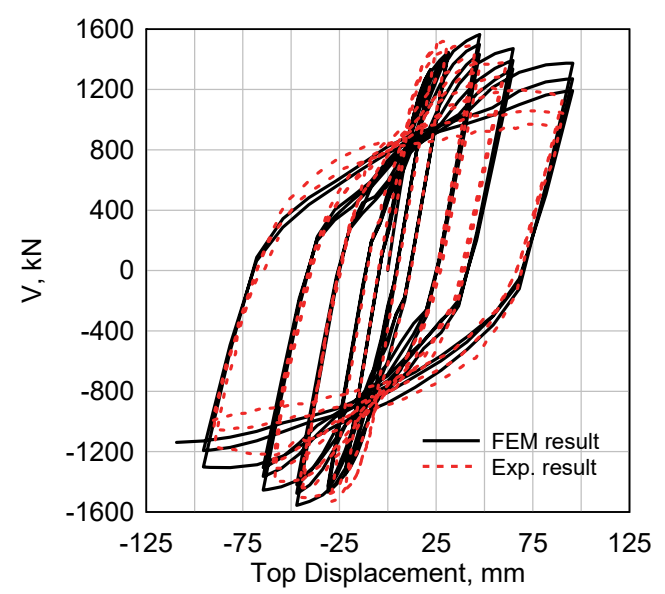

Figure 3: Compare between results of experimental and numerical for WC4T specimen

\begin{tabular}{ccccccc}
\hline Result & \multicolumn{3}{c}{ Positive Direction } & \multicolumn{3}{c}{ Negative Direction } \\
$\mathrm{V}$ max, $\mathrm{kN}$ & Exp. & FEA & Error, $\%$ & Exp. & FEA & Error, \% \\
$\mathrm{K}_{\mathrm{i}}, \mathrm{kN} / \mathrm{mm}$ & 1520 & 1563.1 & 2.8 & -1526 & -1555.9 & 2.0 \\
\hline
\end{tabular}

Table 3: Cyclic results of experimental test and present FEA for WC4T specimen. 


\section{EFFECT OF PANEL TYPE AND STIFFENER SHAPE}

o show the effect of panel type and stiffeners cross-section shape, the results of the models PW, SPW-HL, SPWHT, and SPW-HU will be compared and discussed. The models SPW-HL, SPW-HT, and SPW-HU have the same weight for comparison reasons. The hysteretic behavior was recorded.

Hysteretic behavior of PW, and SPW-HL, SPW-HT, and SPW-HU are shown in Fig. 4, in which the drift ratio is presented on the $\mathrm{x}$-axis $(\%)$ and load-carrying capacity is presented on the y-axis $(\mathrm{kN})$. The hysteretic curves show that panel type (PW and SPW) and the cross-section shape of stiffeners, which has the same weight, has an obvious effect on the load-carrying capacity. Fig. 4.a shows that both SPW-HU and PW have the same lateral strength mechanism, which depends on TensionField action, which produces a post-buckling load-carrying capacity. It also indicates that SPW-HU has a much plumped hysteretic curve than PW, higher load-carrying capacity, and stiffness. Fig. 4.b shows a comparison between the hysteretic curves of SPWs with different cross-section shapes of stiffeners. Fig. 4.b shows that the stiffeners cross-section shape has a significant effect on seismic behavior when the other properties remain the same. SPW-HU has higher initial stiffness and load-carrying capacity in comparison with the SPW-HL and SPW-HT. The backbones curves can be obtained from the hysteretic curves in both pull and push directions, as shown in Fig. 5. The initial stiffness $\left(\mathrm{K}_{\mathrm{i}}\right)$, the second cyclic stiffness at drift ratio $0.5 \%\left(\mathrm{~K}_{2}\right)$, load-carrying capacity, yield points, and maximum points can be concluded from the backbone curves, as shown in Tab. 4. The yield point is a point, at which local buckling and plastic deformations appear in the system. Symbol $\Delta_{\mathrm{y}}$ is the yield displacement $(\mathrm{mm}), \mathrm{V}_{\mathrm{y}}$ is the yield force $(\mathrm{kN}), \Delta_{\mathrm{m}}$ is the displacement at maximum load-carrying capacity $(\mathrm{mm})$ and $\mathrm{V}_{\mathrm{m}}$ is the maximum load-carrying capacity $(\mathrm{kN})$.

From Fig. 5 and Tab. 4, in the push direction, it can be seen that the stiffened walls SPW-HL, SPW-HT, and SPW-HU had a K2 value higher than PW by about 5.5, 8, and 9\%, respectively. At 4\% drift in the push direction, SPW-HL, SPW-HT, and SPW-HU had a higher load-carrying capacity than PW by about 4, 20,23\%, respectively. The cases of SPW-HU and SPW-HL had the maximum and minimum increasing percentages values. Therefore, the $\mathrm{U}$ stiffeners were studied deeply in the other parametric study.

\begin{tabular}{ccccccc}
\hline Model & Direction & $\mathrm{K}_{\mathrm{i}}, \mathrm{kN} / \mathrm{mm}$ & $\mathrm{K}_{2}, \mathrm{kN} / \mathrm{mm}$ & $\Delta_{\mathrm{y}}, \mathrm{mm}$ & $\mathrm{V}_{\mathrm{y}}, \mathrm{kN}$ & $\mathrm{V}_{\mathrm{m}}, \mathrm{kN}$ \\
\multirow{2}{*}{ PW } & push - & 300.8 & 152.1 & 16.3 & 2479.5 & 3267.1 \\
& pull + & 299.9 & 158.0 & 16.3 & 2855.2 & 3203.3 \\
\hline \multirow{2}{*}{ SPW-HL } & push - & 299.3 & 160.6 & 7.8 & 2426.2 & 3403.4 \\
& pull + & 299.9 & 157.9 & 7 & 2066 & 3464.6 \\
\hline \multirow{2}{*}{ SPW-HT } & push - & 301.0 & 164.1 & 16.3 & 2667 & 3914.0 \\
& pull + & 300.1 & 168.1 & 16.3 & 2864.4 & 3878.8 \\
\hline \multirow{2}{*}{ SPW-HU } & push - & 303.1 & 166.1 & 8.1 & 2472.1 & 4016.8 \\
& pull + & 302 & 162.6 & 8.1 & 2463.2 & 3989.5 \\
\hline
\end{tabular}

Table 4: Cyclic analyses of PW and SPW with different stiffener's cross section shape.

\section{EFFECT OF STIFFENER DIRECTION}

7 o show the effect of stiffener's direction on the seismic behavior, the results of the models SPW-HU, SPW-VU, SPW-CU, and SPW-DU will be compared and discussed deeply. The models SPW-HU, SPW-VU, SPW-CU had the same weight, while SPW-DU had higher weight than other models. The hysteretic curves of SPW-HU, SPWVU, SPW-CU, and SPW-DU were presented and compared to PW in this section, as shown in Fig. 6.a and b. Fig. 6.a compares between the hysteretic curve of stiffened walls SPW-VU, SPW-CU, and SPW-DU to horizontally stiffened wall SPW-HU. From Fig. 6.a, it can be observed that SPW-DU had higher initial stiffness and load-carrying capacity than other stiffened walls in the first stages. However, in the last stages, SPW-HU had a higher load-carrying capacity than SPW-DU. This might be attributed to diagonal stiffeners, which increase the diagonal stiffness, where tension fields form. Fig. 6.b shows that using horizontally and diagonally stiffeners increase initial stiffness and load-carrying capacity especially 
diagonally stiffeners in the first stages. Backbone curves for SPWs with different directions were extracted in pull and push directions from all hysteretic curves, as shown in Fig. 7. Initial stiffness, load-carrying capacity, and feature points were extracted from backbone curves for all models, as shown in Tab. 5.

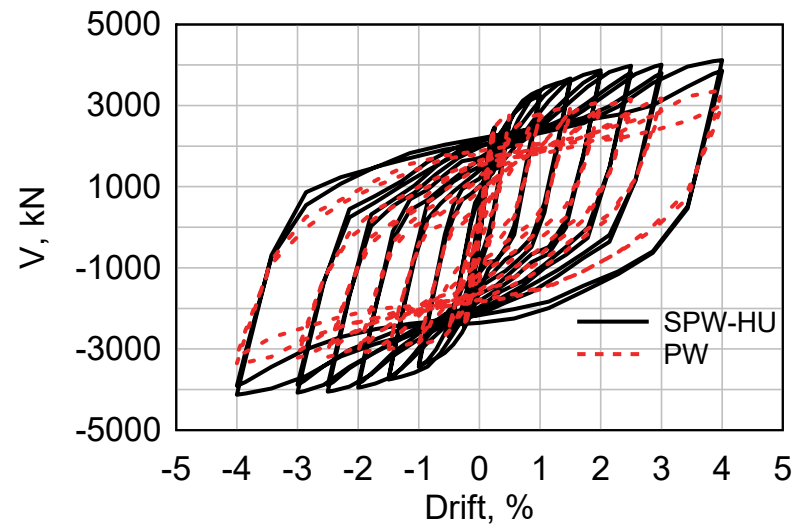

a)

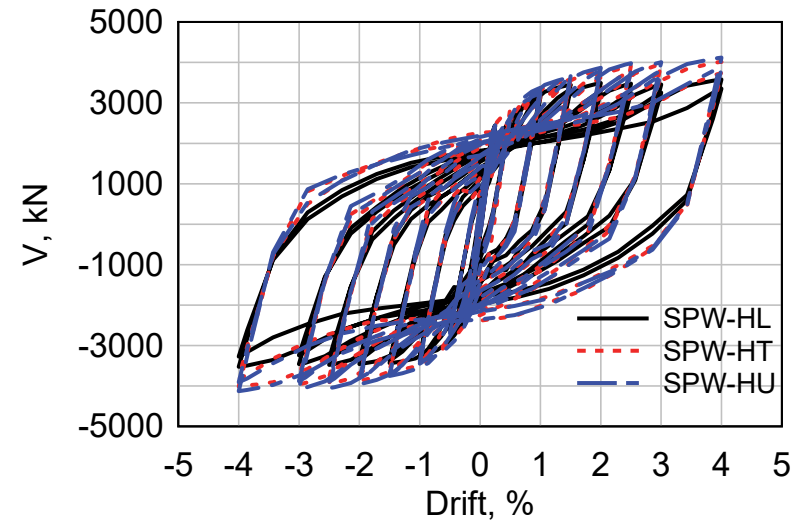

b)

Figure 4: Hysteretic curves of systems. (a) PW and SPW-HU, (b) SPW-HL, SPW-HT, and SPW-HU

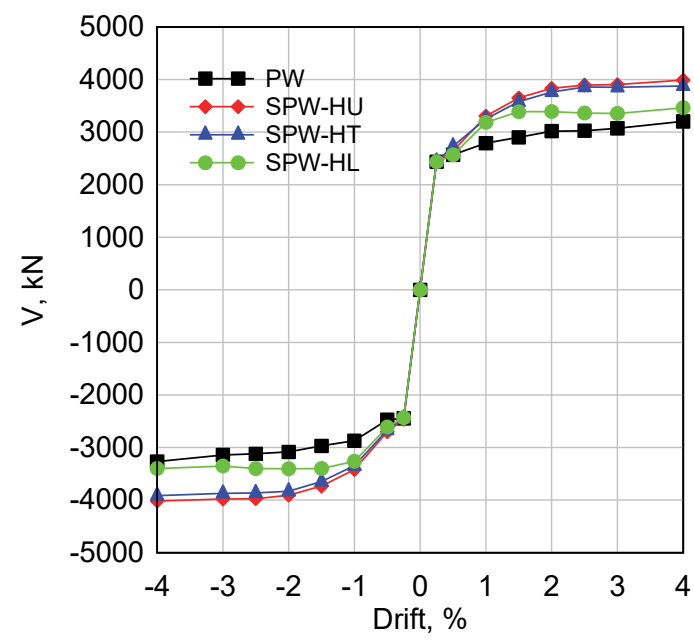

Figure 5: Backbone curves of PW, SPW-HL, SPW-HT, and SPW-HU.

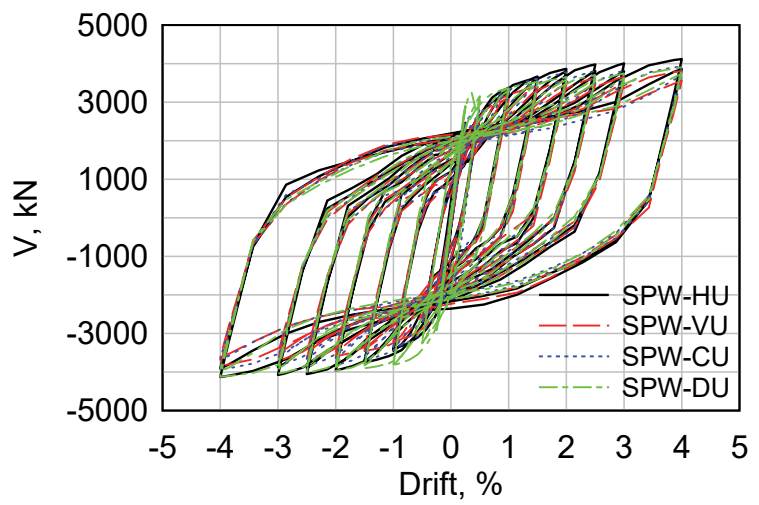

a)

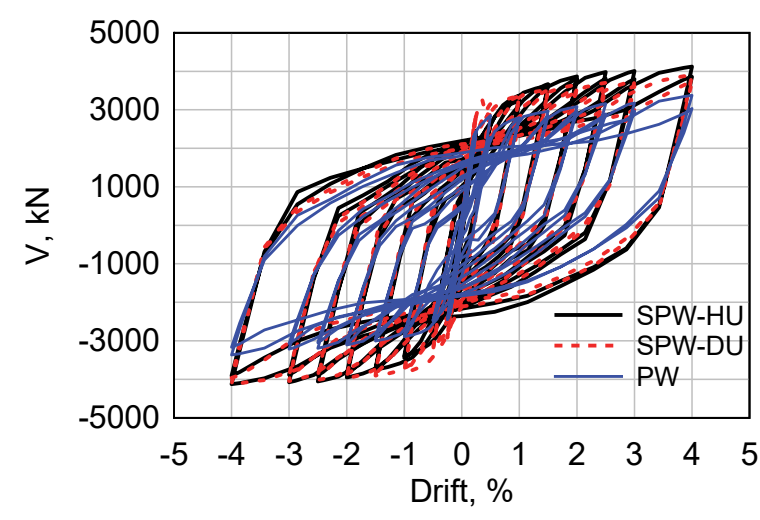

b)

Figure 6: Hysteretic curves of systems. (a) SPW-HU, SPW-VU, SPW-CU, and SPW-DU, (b) SPW-HU, SPW-DU, and PW. 


\begin{tabular}{ccccccc}
\hline Model & Direction & $\mathrm{K}_{\mathrm{i}}, \mathrm{kN} / \mathrm{mm}$ & $\mathrm{K}_{2}, \mathrm{kN} / \mathrm{mm}$ & $\Delta_{\mathrm{y}}, \mathrm{mm}$ & $\mathrm{V}_{\mathrm{y}}, \mathrm{kN}$ & $\mathrm{V}_{\mathrm{m}}, \mathrm{kN}$ \\
\multirow{2}{*}{ PW } & push - & 300.8 & 152.1 & 16.3 & 2479.5 & 3267.1 \\
& pull + & 299.9 & 158.0 & 16.3 & 2855.2 & 3203.3 \\
\hline \multirow{2}{*}{ SPW-HU } & push - & 303.1 & 166.18 & 8.1 & 2472.1 & 4016.8 \\
& pull + & 302 & 162.6 & 8.1 & 2463.2 & 3989.5 \\
\hline \multirow{2}{*}{ SPW-VU } & push - & 246.6 & 162.0 & 5 & 1726.4 & 3730.7 \\
& pull + & 277.0 & 162.3 & 8.2 & 2432.1 & 3687.6 \\
\hline \multirow{2}{*}{ SPW-CU } & push - & 303.4 & 165.6 & 8.2 & 2474.3 & 3809.0 \\
& pull + & 302.3 & 172.9 & 16.3 & 2713 & 3803.6 \\
\hline \multirow{2}{*}{ SPW-DU } & push - & 357.9 & 199.2 & 8.1 & 2899.1 & 4043.3 \\
& pull + & 356.1 & 197.1 & 8.1 & 2879.8 & 3823.4 \\
\hline
\end{tabular}

Table 5: Cyclic analyses of SPW with different stiffener's directions.

From Fig. 7 and Tab. 5, in the push direction, it can be concluded that stiffened wall with different stiffeners directions SPW-HU, SPW-VU, SPW-CU, and SPW-DU had a K2 value higher than PW by about 9.2, 6.5, 9, and 31\%, respectively. At the $4 \%$ drift in the push direction, it can be observed that the load-carrying capacity for stiffened walls increased by percentage values of $23,14,17$, and $23 \%$, respectively. The cases of SPW-HU and SPW-VU had the maximum and minimum increasing percentage values. This might be attributed to the accordion effect, which means that the stiffeners increase the system stiffness in its direction. Therefore, the horizontal stiffeners had better seismic behavior than vertical stiffeners.

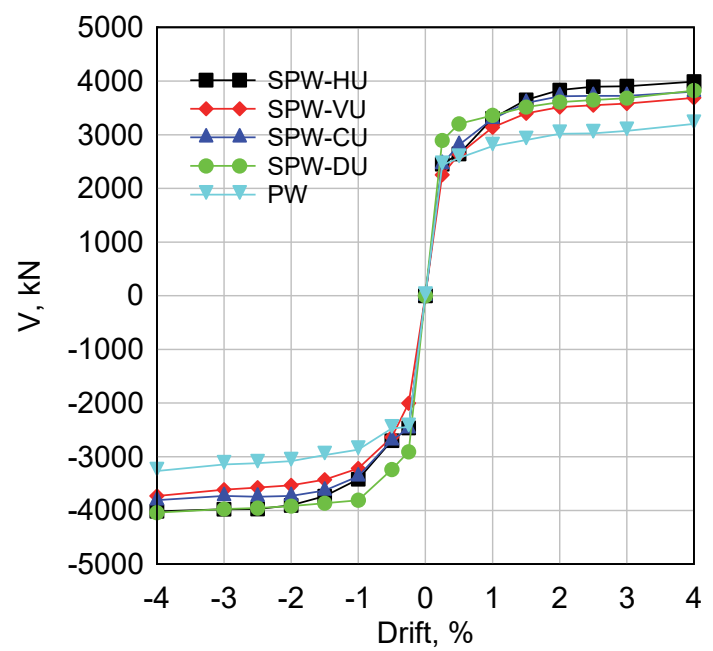

Figure 7: Backbone curves of PW, SPW-HU, SPW-VU, SPW-CU, and SPW-DU

\section{Properties DEgRAdATION AND ENERGY DisSIPATION CAPACITY}

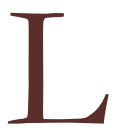

ateral strength degradation reflects the system plastic deformations, columns local failure, and the damage occurs during the loading process. The strength degradation coefficient $(\eta)$ can be defined as (the ratio between the second and first load-carrying capacity at the same drift ratio).

Fig. 8.a shows the lateral strength degradation ratio $(\eta)$ for different systems, it can be seen that $\eta$ are varying between 0.85 and 1 except the second cycle of PW at the drift ratio $0.5 \%$, where $\eta$ is about 0.8 . This might be attributed to the initial yielding of the system. The cyclic stiffness $(\mathrm{Ki})$ describes the stiffness degradation for the different models during the loading process. Ki can be calculated by the method described in Ref [28] as Errore. L'origine riferimento non è stata trovata.. 


$$
K_{i}=\sum_{i=1}^{n} p_{j}^{i} / \sum_{i=1}^{n} \Delta_{j}^{i}
$$

where, $P_{j}^{i}$ is peak lateral shear capacity in each cycle and $\Delta_{j}^{i}$ is peak displacement for each cycle drift.

Fig. 8.b shows the stiffness degradation for PW and SPWs. It can be seen that stiffness degradation decreases stably during the cyclic loading process. The cases of SPW-HU and PW had maximum and minimum stiffness values.

Energy dissipation capacity reflects the seismic performance of the lateral resisting system. The energy dissipation capacity for each cycle is equal to the enclosed area of each hysteretic curve. The much plump the hysteretic curve is the more dissipated capacity. Fig. 9. a shows the energy dissipation capacity for PW, SPW-HL, SPW-HT, and SPW-HU for cyclic number $\mathrm{N}=16$. From Fig. 9.a, it can be concluded that the stiffener cross-section shape had a significant effect on the system energy dissipation capacity. The stiffeners increase the energy dissipation capacity in the stiffened walls SPW-HL, SPW-HT, and SPW-HU by percent values of 28,46 , and $50 \%$, respectively. The cases of the SPW-HU and SPW-HL had the maximum and minimum increasing values. It was found that $\mathrm{U}$ stiffeners had the best seismic behavior. Therefore, $\mathrm{U}$ stiffeners will be studied deeply in the following parametric study. Fig. 9.b shows the accumulated energy dissipation capacity for PW and SPW-HU, SPW-VU, SPW-CU, and SPW-DU for cyclic number N=16. From Fig. 9.b, it can be observed that the stiffener's direction has a significant effect on the wall energy-dissipation capacity. The stiffeners caused energydissipation capacity increasing in the stiffened walls SPW-HU, SPW-VU, SPW-CU, and SPW-DU by percentage values of 50, 39, 44, and 57\%, respectively. The cases of SPW-DU and SPW-VU had the maximum and minimum increasing percentage values. This might be attributed to the diagonal stiffeners, which increased the rigidity in the diagonal direction, where the diagonal tension field action occurred.

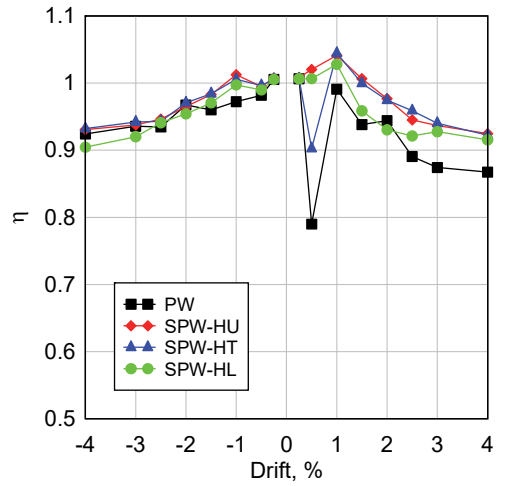

a)

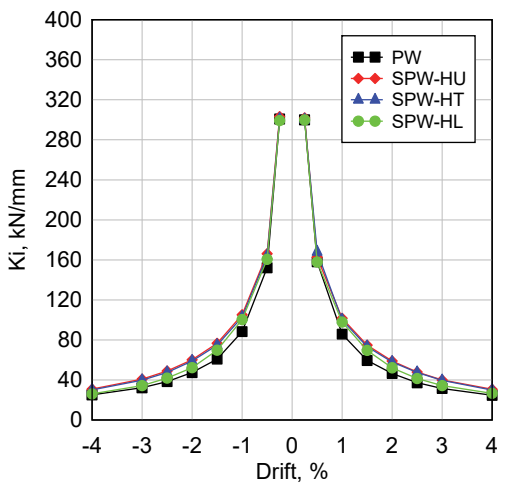

b)

Figure 8: Degradation characteristics. a) Strength degradation. b) Stiffness degradation.

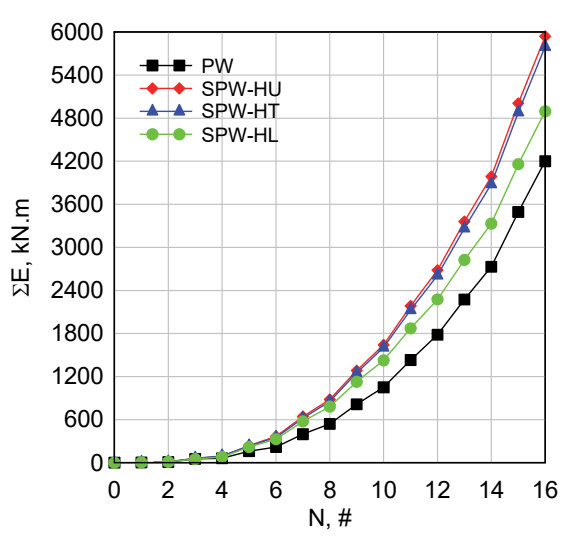

a) Effect of stiffener shape.

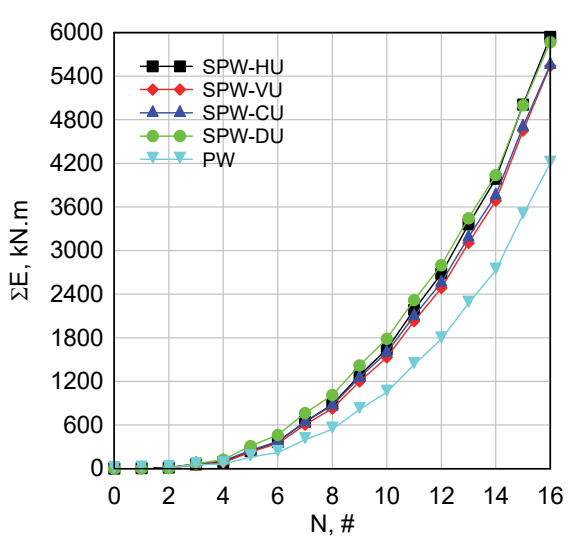

b) Effect of stiffener direction.

Figure 9: Accumulated energy dissipation capacity for $\mathrm{N}=16$. 


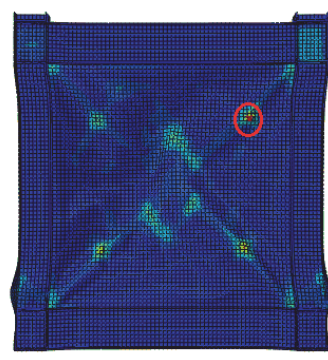

a) PW

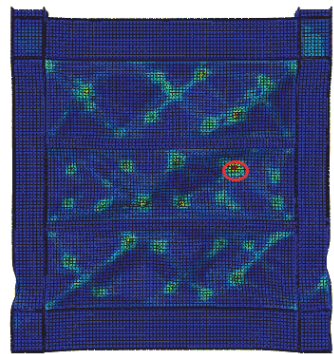

d) SPW-HU

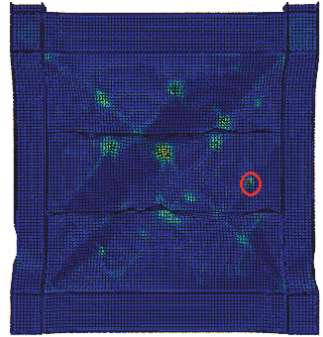

b) SPW-HL

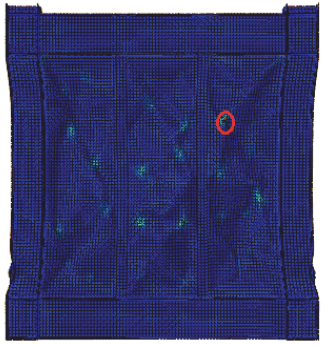

e) SPW-VU

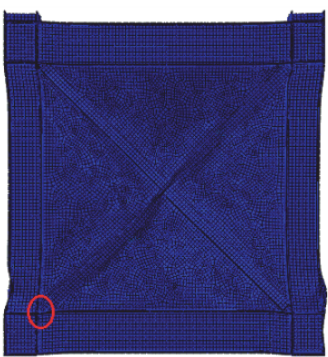

g) SPW-DU

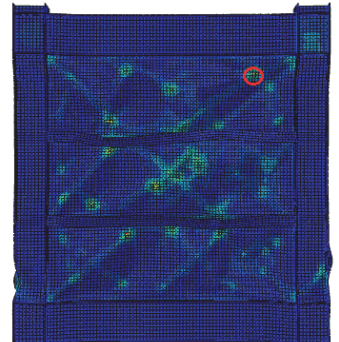

c) SPW-HT

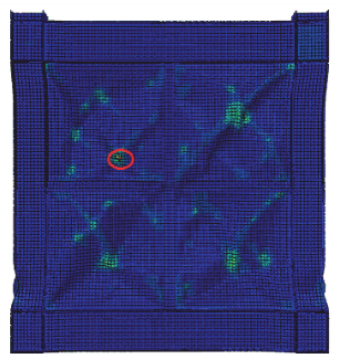

f) SPW-CU

Figure 10: Comparison of PEEQ distribution at drift $4 \%$

\section{COMPARISON OF FRACTURE TENDENCY AND FAILURE MODES}

$\mathrm{T}$

he equivalent plastic strain (PEEQ) describes the fracture tendency as a cumulative variable [19]. The maximum PEEQ values are the actual fracture zones. Therefore, in practical engineering, these results can be used to avoid fractures in advance. Fig. 10 shows the PEEQ distributions of PW and SPWs. Tab. 6 shows the maximum PEEQ and out-of-plane deformations $(\mathrm{mm})$. It can be seen that the stiffener details can change PEEQ, failure modes, and deformation distributions. The PEEQ values of stiffened walls SPW-HL, SPW-HT, SPW-HU, SPW-VU, SPW-CU, and SPW-DU are higher than PW by about 64, 31, 21, 203, 87, and $1116 \%$, respectively. This might be attributed to the stress concentration, local buckling of stiffeners. The plastic strain accumulation of SPW-DU increased at the corners due to the effect of both diagonal tension fields and diagonal stiffeners, so higher columns stiffness are needed to avoid the columns fracture. Tab. 6 also shows the maximum out-of-plane deformations, in which the deformation of SPW-HU is the smallest, showing that the deformations are effectively restrained by the horizontal U stiffeners. One main wave was formed in the case of PW with clear two-way tension fields. For SPW-HL, SPW-HT, SPW-HU, SPW-VU, and SPW-CU tension fields were formed in stiffener compartments. In the case of SPW-DU, the maximum deformation occurred at the stiffeners intersection due to limited stiffeners stiffness and a main wave failure mode can be observed. 


\begin{tabular}{ccc}
\hline Model ID & PEEQ & FINAL POSITION \\
PW & 1.9 & 264 \\
SPW-HL & 3.12 & 179 \\
SPW-HT & 2.49 & 176 \\
SPW-HU & 2.29 & 117 \\
SPW-VU & 5.76 & 157 \\
SPW-CU & 3.56 & 161 \\
SPW-DU & 23.1 & 307 \\
\hline
\end{tabular}

Table 6: Comparison of the equivalent plastic strains and the out-of-plane deformations (mm) at drift 4\%.

\section{CONCLUSIONS}

$\mathrm{I}$ $\mathrm{n}$ this paper, nonlinear cyclic analyses were conducted using numerical simulation and finite element models for PW and SPW, to investigate the influence of panel type, stiffeners cross-section shape, and stiffeners direction on loadcarrying capacity, stiffness, and energy dissipation capacity. The main topic focused on this paper is the seismic behavior of stiffened steel walls with different stiffeners characteristics, which have the same weight. This paper provides an economic evaluation for the practical engineer. Based on the current study numerical simulation and parametric study, some conclusions are shown as follows:

- Finite element models were created and validated with published experimental and numerical works. The models were able to predict the load-carrying capacity and the system stiffness of the previous results with a percentage error of $3 \%, 1.5 \%$, respectively.

- The stiffener's cross-section shape has a greater impact on the load-carrying capacity than the wall stiffness. Horizontally stiffened wall with $\mathrm{U}$ stiffeners has higher load-carrying capacity than $\mathrm{L}$, and $\mathrm{T}$ stiffeners by about $18 \%$, and $3 \%$, respectively.

- SPW with horizontal U stiffeners has higher stiffness, load-carrying capacity, and energy-dissipation capacity than PW by about 9,23 , and $50 \%$, respectively. While, SPW-DU has a higher energy-dissipation capacity than PW by about $57 \%$.

- The appropriate stiffener details can effectively improve the fracture properties and failure modes. The out-of-plane deformations of SPW-HL, SPW-HT, SPW-HU, SPW-VU, and SPW-CU were effectively lessened. Using horizontal $\mathrm{U}$ stiffeners reduced deformations by about $56 \%$. Diagonal stiffeners increase the effects of tension fields on the columns, so higher column stiffness is needed to avoid columns fracture.

- In the high seismic zones, economic performance should be taken into account to choose appropriate stiffener characteristics. The proposed horizontal and diagonal U stiffeners effectively improve seismic behavior, fracture behavior, and energy-dissipation capacity. This paper achieves the combination of high-performance stiffeners form an

- d performance material for improving the seismic behavior of stiffened steel walls.

\section{REFERENCES}

[1] Youssef, N., Wilkerson, R., Fischer, K., Tunick, D. (2010). Seismic performance of a 55-storey steel plate shear wall, Struct. Des. Tall Spec. Build., 19(1-2), pp. 139-165, DOI: 10.1002/tal.545.

[2] Alavi, E., Nateghi, F. (2013). Experimental study on diagonally stiffened steel plate shear walls with central perforation, J. Constr. Steel Res., 89(1), pp. 9-20, DOI: 10.1016/j.jcsr.2013.06.005.

[3] Alinia, M.M., Dastfan, M. (2007). Cyclic behaviour, deformability and rigidity of stiffened steel shear panels, J. Constr. Steel Res., 63(4), pp. 554-563, DOI: 10.1016/j.jcsr.2006.06.005.

[4] Guo, H.C., Li, Y.L., Liang, G., Liu, Y.H. (2017). Experimental study of cross stiffened steel plate shear wall with semirigid connected frame, J. Constr. Steel Res., 135(1), pp. 69-82, DOI: 10.1016/j.jcsr.2017.04.009.

[5] Cao, C.H., Hao, J.P., Zhong, W.H., Li, F., Wang, Y.C. (2008).Cyclic test of diagonal stiffened steel plate shear walls. The 10th International Symposium on Structural Engineering for Young Experts, Changsha, 19-21 October. 
[6] Vian, D., Bruneau, M., Purba, R. (2009). Special perforated steel plate shear walls with reduced beam section anchor beams. II: Analysis and design recommendations, J. Struct. Eng., 135(3), pp. 221-228, DOI: 10.1061/(ASCE)07339445(2009)135:3(221).

[7] Thorburn, L.J., Montgomery, C.J., Kulak, G.L. (2012). Analysis of Steel Plate Shear Walls, Department of Civil Engineering, University of Alberta.

[8] Driver, R.G., Kulak, G.L., Kennedy, D.J.L., Elwi, A.E. (1998). Cyclic test of four-story steel plate shear wall, J. Struct. Eng., 124(2), pp. 112-120, DOI: 10.1061/(ASCE)0733-9445(1998)124:2(112).

[9] Nie, J., Fan, J., Liu, X., Huang, Y. (2013). Comparative study on steel plate shear walls used in a high-rise building, J. Struct. Eng. (United States), 139(1), pp. 85-97, DOI: 10.1061/(ASCE)ST.1943-541X.0000613.

[10] Hitaka, T., Matsui, C. (2003). Experimental study on steel shear wall with slits, J. Struct. Eng., 129(5), pp. 586-595, DOI: 10.1061/(ASCE)0733-9445(2003)129:5(586).

[11] Chen, S.J., Jhang, C. (2011). Experimental study of low-yield-point steel plate shear wall under in-plane load, J. Constr. Steel Res., 67(6), pp. 977-985, DOI: 10.1016/j.jcsr.2011.01.011.

[12] Caccese, V., Elgaaly, M., Chen, R. (1993). Experimental study of thin steel-plate shear walls under cyclic load, J. Struct. Eng. (United States), 119(2), pp. 573-587, DOI: 10.1061/(ASCE)0733-9445(1993)119:2(573).

[13] Li, F., Li, H., Li, Z.M., Li, Z.J., Chen, X.F., Ding, L. (2009). Cyclic test of diagonally stiffened steel plate shear wall, J. Xi'an Univ. Archit. Technol., 41(1), pp. 57-62.

[14] Choi, I.R., Park, H.G. (2009). Steel plate shear walls with various infill plate designs, J. Struct. Eng., 135(3), pp. 785-796, DOI: 10.1061/(ASCE)0733-9445(2009)135:7(785).

[15] Nakashimal, M., Akazawa, T., Tsuji, B. (1995). Strain-hardening behavior of shear panels made of low-yield steel. II: Model, J. Struct. Eng., 121(12), pp. 1750-1757, DOI: 10.1061/(ASCE)0733-9445(1995)121:12(1750).

[16] Shi, Y., Wang, M., Wang, Y. (2011). Experimental and constitutive model study of structural steel under cyclic loading, J. Constr. Steel Res., 67(8), pp. 1185-1197, DOI: 10.1016/j.jcsr.2011.02.011.

[17] Nakashima, M., Iwai, S., Iwata, M., Takeuchi, T., Konomi, S., Akazawa, T., Saburi, K. (1994). Energy dissipation behaviour of shear panels made of low yield steel, Earthq. Eng. Struct. Dyn., 23(12), pp. 1299-1313, DOI: 10.1002/eqe.4290231203.

[18] Chen, S.J., Jhang, C. (2006). Cyclic behavior of low yield point steel shear walls, Thin-Walled Struct., 44(7), pp. 730-738, DOI: $10.1016 /$ j.tws.2006.08.002.

[19] Abaqus., Simulia, D.S., Fallis, A., Techniques, D. (2013). Abaqus Analysis User's Guide (6.14)., Abaqus 6.12, , DOI: 10.1017/CBO9781107415324.004.

[20] Park, H.G., Kwack, J.H., Jeon, S.W., Kim, W.K., Choi, I.R. (2007). Framed steel plate wall behavior under cyclic lateral loading, J. Struct. Eng., 133(3), pp. 378-388, DOI: 10.1061/(ASCE)0733-9445(2007)133:3(378).

[21] Sabelli, R., Bruneau, M. (2006). Steel Plate Shear Walls (Steel Design Guide 20), Chicago, American Institute of Steel Construction, Inc.

[22] AISC. (2010). Seismic Provisions for Structural Steel Buildings, Chicago, American Institute of Steel Construction, Inc.

[23] El Emam, H.M., El-Sisi, A.E.M., Salim, H.A., Sallam, H.E.M. (2015).Cyclic deformation at the tip of inclined cracks in steel plates. Pressure Vessels and Piping Conference (ASME 2015 ), 6A-2015, Boston.

[24] Sallam, H.E.M., Matar, E.B., El-Sisi, A.E., El-Hussieny, O.M. (2009).Crack Tip Plasticity of Short Fatigue Crack Emanating from Riveted/Bolted Steel Connections. The 13th International Conference on Structural and Geotechnical Engineering (ICSGE), Cairo.

[25] El-Emam, H., Elsisi, A., Salim, H., Sallam, H. (2018). Fatigue Crack Tip Plasticity for Inclined Cracks, Int. J. Steel Struct., 18(2), DOI: 10.1007/s13296-018-0016-z.

[26] Chaboche, J.L. (1986). Time-independent constitutive theories for cyclic plasticity, Int. J. Plast., 2(2), pp. 149-188, DOI: 10.1016/0749-6419(86)90010-0.

[27] Chaboche, J.L. (1989). Constitutive equations for cyclic plasticity and cyclic viscoplasticity, Int. J. Plast., 5(3), pp. 247302, DOI: 10.1016/0749-6419(89)90015-6.

[28] Nie, J., Qin, K., Cai, C.S. (2008). Seismic behavior of connections composed of CFSSTCs and steel-concrete composite beams-experimental study, J. Constr. Steel Res., 64(10), pp. 1178-1191, DOI: 10.1016/j.jcsr.2007.12.004. 